\title{
DIFICULDADES \\ RECORRENTES DOS \\ ALUNOS DO 5 ANO DO \\ ENSINO FUNDAMENTAL \\ EM MATEMÁTICA
}

CLARILZA PRADO DE SOUSA, TARCISO JOAQUIM DE OLIVEIRA, MARIA CONCEIÇÃO ROCHA, IVO RIBEIRO DE SÁ, SOLANGE MARIA DOS SANTOS, SIMONE DE OLIVEIRA,

\section{RESUMO}

A avaliação de larga escala é realizada no Brasil como instrumento destinado a monitorar e aperfeiçoar o desempenho do sistema educacional, desde a década de 1980. Considerando as dificuldades dos educadores e da população em compreender os resultados oferecidos por essas avaliações em larga escala e a importância dessa dimensão avaliativa para a implantação de políticas públicas mais consistentes, neste estudo analisamos os resultados de três avaliações de um sistema de ensino particular, aplicadas num período de seis anos.

PALAVRAS-CHAVE REPRESENTAÇÕES SOCIAIS • ESCALA DE AVALIAÇÃO • SISTEMA DE EDUCAÇÃO • DIFICULDADES DE APRENDIZAGEM. 


\title{
RESUMEN
}

La evaluación a gran escala se realiza en Brasil, desde la década de 1980, como instrumento destinado a monitorear y perfeccionar el desempeño del sistema educativo. Considerando la dificultad de los educadores y de la población en comprender los resultados ofrecidos por las evaluaciones a gran escala y la importancia de esa dimensión evaluativa para la implantación de políticas públicas más consistentes, en el presente estudio analizamos los resultados de tres evaluaciones de un Sistema de Enseñanza particular, aplicadas en un período de seis años.

PALABRAS CLAVE REPRESENTACIONES SOCIALES •

ESCALA DE RENDIMIENTO • SISTEMAS DE EDUCACIÓN •

INCAPACIDAD PARA EL APRENDIZAJE.

\begin{abstract}
Large-scale evaluation as a tool to monitor and improve the performance of the education system has been carried out in Brazil since the 1980s. Considering the difficulties of the population and educators in understanding the results offered by large-scale assessments and the importance of this evaluative dimension to the implementation of more effective public policies, this study analyzes the results of three evaluations of a private educational institution, carried out over a six-year period.

KEYWORDS SOCIAL REPRESENTATIONS • ACHIEVEMENT

EVALUATION・EDUCATION SYSTEMS・LEARNING

DISABILITIES.
\end{abstract}




\section{INTRODUÇÃO}

A avaliação de larga escala, no Brasil, principalmente a partir dos anos 1980, tem contribuído para monitorar o desempenho escolar dos alunos da educação básica e, nesse sentido, passou a ser um componente relevante no estudo de políticas públicas voltadas à educação. A potencialidade desse tipo de análise de competência induziu a proposição de inúmeros outros processos e sistemas avaliativos.

Tal modalidade teve início com o Sistema de Avaliação da Educação Básica (Saeb), que analisa o desempenho dos alunos da educação básica em Língua Portuguesa e Matemática. Na sequência, inúmeros sistemas de avaliação complementares ao Saeb foram criados, cada um deles procurando analisar aspectos ou níveis de ensino específicos, e muitos acumulando análise sobre a mesma perspectiva. Entre eles, citam-se: a Avaliação Nacional da Educação Básica (Aneb), que é aplicada a uma amostra da população composta por alunos de $5^{\circ}$ e $9^{\circ}$ anos do ensino fundamental e $3^{\circ}$ ano do ensino médio das redes públicas e privadas de todo o país, localizados tanto na zona urbana quanto rural; a Prova Brasil - Avaliação Nacional do Rendimento 
Escolar (Anresc), que é aplicada em forma de censo aos alunos de $5^{\circ}$ e $9^{\circ}$ anos do ensino fundamental somente das escolas públicas; o Exame Nacional para Certificação de Competências de Jovens e Adultos (Encceja), que analisa as habilidades e competências básicas de jovens e adultos que não tiveram oportunidade de acesso à escolaridade regular na idade apropriada.

Mesmo o Exame Nacional do Ensino Médio (Enem), criado com a perspectiva de influir no currículo da educação básica, criou força posteriormente como instrumento de seleção para universidades, substituindo, em muitos casos, o vestibular. A expressiva adesão a esse exame fez com que, atualmente, ele represente um sistema censitário de avaliação.

No Estado de São Paulo, a exemplo de muitos estados, há o Sistema de Avaliação de Rendimento Escolar do Estado de São Paulo (Saresp), que objetiva avaliar o desempenho dos alunos do $3^{\circ}, 5^{\circ}, 7^{\circ}$ e $9^{\circ}$ anos do ensino fundamental e da $3^{a}$ série do ensino médio, nas disciplinas de Língua Portuguesa e Matemática, e dele participam escolas da rede pública e privada.

A implantação desses sistemas e a publicação das análises realizadas têm contribuído de forma significativa para mudanças de expectativas em relação ao sistema de ensino e mesmo para a construção de uma visão mais contextualizada dos resultados das aprendizagens dos alunos (BROOKE, SOARES, 2008).

Inicialmente, os estudos de avaliação se voltavam mais especificamente para a análise do acesso e permanência do aluno na escola, isto é, da capacidade que o sistema de ensino apresentava para atender as crianças em idade escolar. Atualmente, as avaliações de larga escala têm focado, principalmente, o nível de desempenho dos estudantes e as aprendizagens adquiridas no processo escolar, caminhando para a compreensão das associações entre aprendizagem e características das escolas, dos pais, do desempenho, da formação dos professores, das condições socioeconômicas dos docentes e das condições estruturais dos sistemas de ensino.

Tais associações permitem compreender o desempenho do aluno, construído com base no contexto social e na sua trajetória de vida. No entanto, se a continuidade desses estudos tem, por um lado, permitido aos dirigentes da educação terem uma visão geral da qualidade e equidade do sistema de ensino, por outro lado a sua realização, sem que medidas políticas 
consequentes de revisão tenham sido percebidas pelos educadores, tem levado a indagações sobre a efetividade desses processos avaliativos:

[...] a sofisticação técnica da avaliação nacional - que hoje ocupa a atenção da cúpula decisória e de seus assessores apresenta-se como entrave para a compreensão; tanto pelos atores dos sistemas e escolas como pela população em geral, do processo avaliativo realizado. (FREITAS, 2004, p. 685)

Estudos indicam que há claramente uma defasagem entre o diagnóstico realizado, as recomendações propostas e o planejamento consequente, resultantes dessas avaliações (TAVARES, 2012).

As avaliações têm possibilitado um diagnóstico global importante das dificuldades e facilidades alcançadas pelos alunos. No entanto, as recomendações originárias desses exames são ainda incipientes, gerais e, muitas vezes, de senso comum. Identificada a dificuldade dos estudantes em operações com frações, por exemplo, recomenda-se treinamento aos professores sobre esse tópico do conteúdo. Em Língua Portuguesa, quando observada a dificuldade dos alunos na compreensão de texto, propõe-se capacitação de professores para o desenvolvimento de leitura e interpretação de textos.

Percebe-se, portanto, que a avaliação precisaria também analisar alternativas de superação das dificuldades, observando estratégias que vêm se apresentando eficazes, para oferecer aos processos de planejamento, opções mais efetivas do que as atualmente propostas, até mesmo aquelas que tenham sido idealizadas sem o embasamento em nenhuma avaliação em larga escala.

Diante desse cenário, o objetivo deste artigo é evidenciar um posicionamento crítico e analisar como os processos de planejamento têm considerado os diagnósticos realizados por meio das avaliações em larga escala, além de destacar de que maneira a sofisticação técnica dos sistemas de avaliação, como assinala Freitas (2004), pode contribuir para o desenvolvimento de processos de planejamentos mais consequentes. Visa, também, a compreender como os resultados de avaliações de larga escala vêm sendo apropriados por professores. 
Para tanto, serão analisados os resultados da disciplina de Matemática apresentados pelos alunos do $5^{\circ}$ ano, antiga $4^{\circ}$ série, obtidos na aplicação do Saeb e do Saresp em um sistema de ensino particular, no período de 2006 a 2008, referente a três avaliações de larga escala.

As análises desses resultados evidenciaram a presença de dificuldades, denominadas neste estudo como dificuldades recorrentes, que persistiram durante os seis anos considerados na pesquisa em todas as turmas de alunos do $5^{\circ}$ ano e que suscitam as seguintes indagações: por que tais dificuldades continuaram em todos esses anos? Como as dificuldades vinham sendo identificadas pelo sistema de ensino? Quais as medidas tomadas no sentido de planejar a superação de tais dificuldades? Como os professores identificam tais dificuldades?

Na primeira etapa, foram identificadas as dificuldades recorrentes, em Matemática, dos alunos do $5^{\circ}$ ano. Em seguida, foi feita uma análise do currículo do $1^{\circ}$ ao $5^{\circ}$ ano comparando as dificuldades encontradas com as expectativas de ensino e aprendizagem. Na terceira etapa foram consultados os professores cujos alunos apresentavam maiores dificuldades nos últimos seis anos, procurando analisar a visão que apresentavam em relação a essas dificuldades.

A análise das respostas dos docentes foi embasada na Teoria das Representações Sociais, de Moscovici (1961; 1978; 2003; 2012), que permitiu identificar quais as proposições e as hipóteses que os professores apresentavam sobre tais dificuldades.

Para Moscovici (2012, p. 62), as proposições e avaliações se organizam em três dimensões: atitudes, informações e imagem sobre determinado objeto social. $\mathrm{O}$ autor entende que informações são "dimensões ou conceitos - se refere à organização dos conhecimentos que um grupo possui a respeito de um objeto social" que, analogamente neste estudo são as dificuldades recorrentes dos alunos. A atitude é a dimensão que determina a orientação do conhecimento identificado na primeira dimensão. Finalmente, a imagem de uma representação se refere a uma ideia de modelo social, construído sobre o objeto da representação.

O processo de construção de uma representação social em sua tríplice dimensão se organiza a partir de dois processos: ancoragem e objetivação. Ancorar é encontrar ligações sociais, 
históricas e contextuais que permitem articulação de um objeto a processos psicossociais; objetivar, em termos gerais, é dar forma, construir um modelo social de um objeto.

Nesse sentido, a análise das representações permitirá verificar os conhecimentos e atitudes que os professores aplicam frente aos desafios que são as dificuldades dos alunos, e quais as imagens que constroem dessas dificuldades. Possibilitará, também, analisar como tais dificuldades vêm sendo objetivadas e quais os embasamentos que as sustentam.

\section{1ª ETAPA: IDENTIFICAÇÃO DAS DIFICULDADES RECORRENTES DOS ALUNOS EM MATEMÁTICA}

A primeira Etapa consistiu-se na análise dos relatórios dos resultados das avaliações de larga escala efetuadas no Sistema de Ensino escolhido, realizados em 2003, 2005 e 2008. Considerando que uma avaliação leva quase um ano para ter seus resultados divulgados no Sistema de Ensino, a observação nas três Etapas poderia ser estimada para os seis anos de análise dos resultados - 2003 a 2008.

Nos estudos realizados observou-se uma recorrência de baixos resultados em alguns descritores de Matemática. Os descritores de habilidades em que os alunos de $4^{\mathrm{a}}$ série $/ 5^{\circ}$ ano apresentaram maior dificuldade na área de Matemática foram identificados por sua recorrência nas análises. Assim, foram selecionados aqueles que permaneceram em duas ou três avaliações e que tiveram menos de $50 \%$ de acerto, resultando em oito descritores.

O quadro 1 apresenta as dificuldades recorrentes identificadas na análise. Observa-se que, entre os descritores das habilidades apresentados, dois estão presentes no campo geométrico, três no campo das grandezas e medidas e três no campo numérico.

Os resultados apresentados indicam uma persistência de dificuldades que as ações propostas pelo sistema de ensino parecem não ter conseguido superar. 
QUADRO 1 - Descritores das habilidades em que os alunos apresentaram maior porcentagem de erro em, pelo menos, duas avaliações

\begin{tabular}{|c|c|c|}
\hline HABILIDADES & $\begin{array}{l}\text { NÚMERO DE } \\
\text { RECORRÊNCIAS } \\
\text { DA DIFICULDADE }\end{array}$ & $\begin{array}{l}\text { ANOS DE } \\
\text { AVALIAÇÃO }\end{array}$ \\
\hline $\begin{array}{l}\text { 1. Identificar semelhanças e diferenças } \\
\text { entre figuras tridimensionais, distinguindo } \\
\text { pirâmides de prismas, fazendo contagem } \\
\text { do número de vértices, arestas ou faces } \\
\text { nos poliedros }\end{array}$ & duas avaliações & $2003 / 2008$ \\
\hline $\begin{array}{l}\text { 2. Identificar características de figuras } \\
\text { bidimensionais como o tipo de contorno } \\
\text { que as delimita }\end{array}$ & três avaliações & $\begin{array}{l}2003,2005 \\
\text { e } 2008\end{array}$ \\
\hline $\begin{array}{l}\text { 3. Resolver problemas utilizando unidades } \\
\text { de medida padronizadas como } \mathrm{km} / \mathrm{m} / \mathrm{cm} / \\
\mathrm{mm} / \mathrm{kg} / \mathrm{g} / \mathrm{mg}\end{array}$ & três avaliações & $\begin{array}{c}2003,2005 \\
\text { e } 2008\end{array}$ \\
\hline $\begin{array}{l}\text { 4. Resolver problema envolvendo o cálculo } \\
\text { de perímetro de figuras planas desenhadas } \\
\text { em malhas quadriculadas }\end{array}$ & três avaliações & $\begin{array}{l}2003,2005 \\
\quad \text { e } 2008\end{array}$ \\
\hline $\begin{array}{l}\text { 5. Utilizar unidades de medida de tempo } \\
\text { e (ou) estabelecer relações entre elas. } \\
\text { Estabelecer relações entre dia e semana, } \\
\text { hora e dia, dia e mês, mês e ano, ano e } \\
\text { década, ano e século, década e século, } \\
\text { século e milênio, hora e minuto, minuto } \\
\text { e segundo }\end{array}$ & duas avaliações & $2003 / 2008$ \\
\hline $\begin{array}{l}\text { 6. Reconhecer e utilizar características } \\
\text { do sistema de numeração decimal, } \\
\text { tais como agrupamentos e trocas na } \\
\text { base } 10 \text {, princípio do valor posicional } \\
\text { e decomposição em ordens }\end{array}$ & três avaliações & $\begin{array}{l}2003,2005 \\
\quad \text { e } 2008\end{array}$ \\
\hline $\begin{array}{l}\text { 7. Identificar a escrita por extenso de } \\
\text { números racionais representados na } \\
\text { forma decimal, reconhecendo a existência } \\
\text { de "ordens" como décimos, centésimos } \\
\text { e milésimos }\end{array}$ & duas avaliações & $2003 / 2005$ \\
\hline $\begin{array}{l}\text { 8. Resolver problemas envolvendo noções } \\
\text { de porcentagem ( } 25 \%, 50 \%, 100 \%)\end{array}$ & duas avaliações & $2005 / 2008$ \\
\hline
\end{tabular}

Fonte: Relatório de avaliação externa dos anos 2003 (FCC), 2005 e 2008 (CESPE/UnB).

\section{ETAPA: ANÁLISE DO CURRÍCULO DO 1AO 5 ANO COMPARANDO AS DIFICULDADES ENCONTRADAS COM AS EXPECTATIVAS DE ENSINO E APRENDIZAGEM}

2 A ação do professor e do educando, estabelecendo um vínculo no processo de ensino Na segunda etapa, foram analisadas as habilidades - pré-requisitos - com base nas dificuldades recorrentes identificadas, que deveriam ter sido desenvolvidas em anos anteriores pelos alunos. Foram verificadas as expectativas de ensino e aprendizagem ${ }^{2}$ e aprendizagem, possibilita a intencionalidade do fazer pedagógico. A organização das expectativas de ensino e aprendizagem revela uma tríade: objetivo/conteúdo/ habilidade-competência. 
do $1^{\circ}$ ao $4^{\circ}$ ano do ensino fundamental relacionadas aos oito descritores apresentados.

\begin{tabular}{|c|c|c|c|}
\hline \multicolumn{2}{|c|}{ 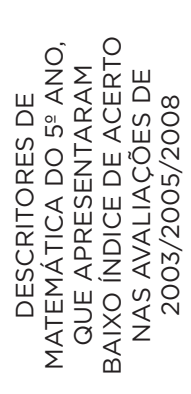 } & 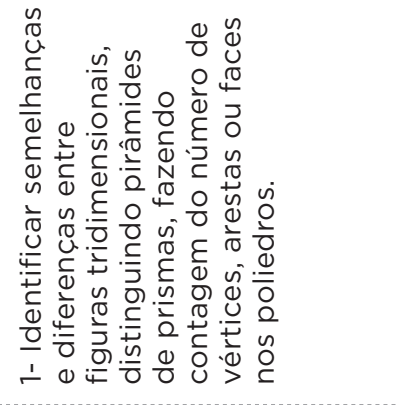 & 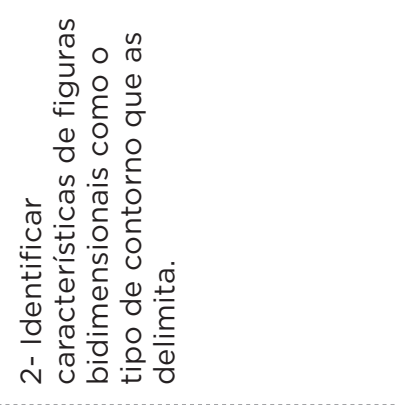 \\
\hline \multirow{4}{*}{ 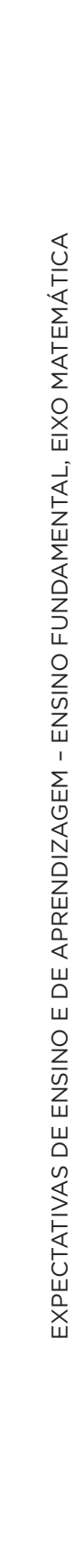 } & 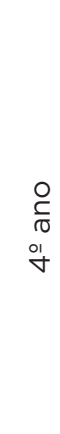 & 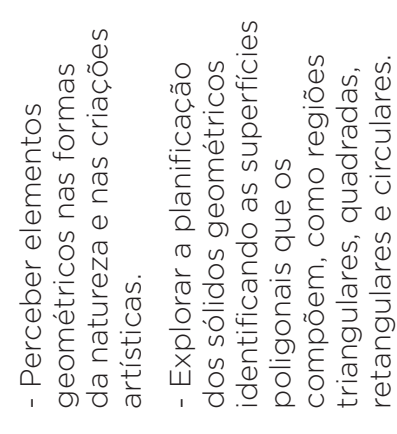 & 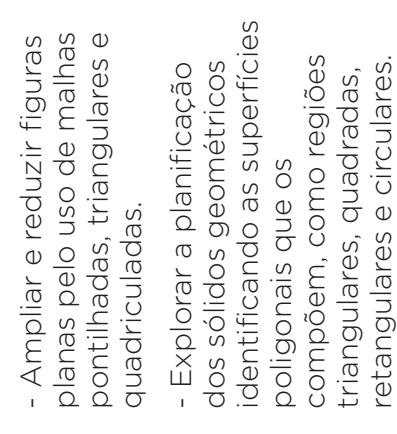 \\
\hline & 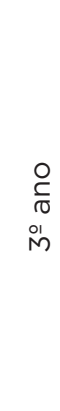 & 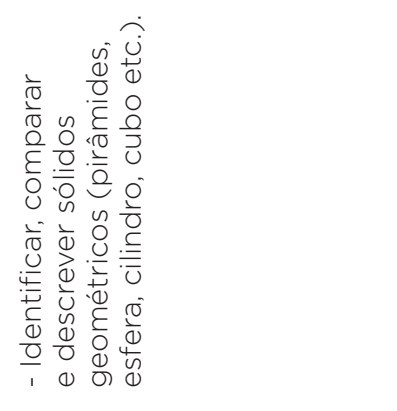 & 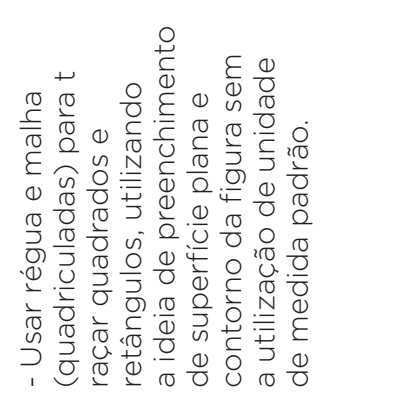 \\
\hline & $\begin{array}{l}\stackrel{0}{0} \\
0 \\
0 \\
\sim\end{array}$ & 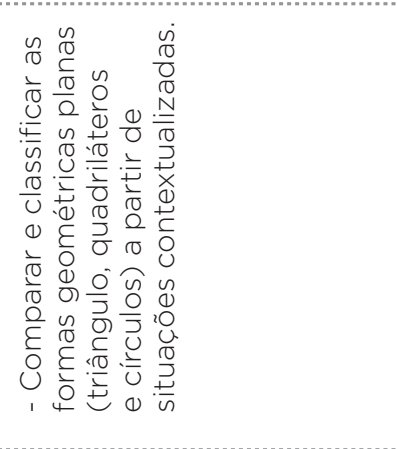 & 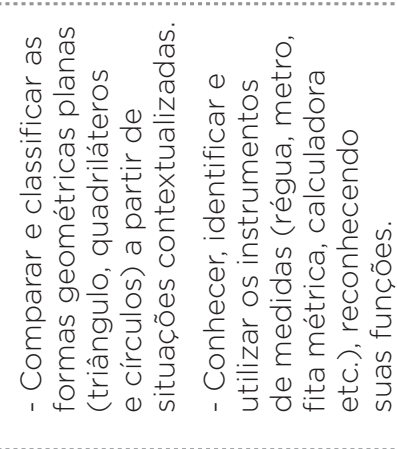 \\
\hline & $\begin{array}{l}\frac{c}{\sigma} \\
\text { ㅇ }\end{array}$ & 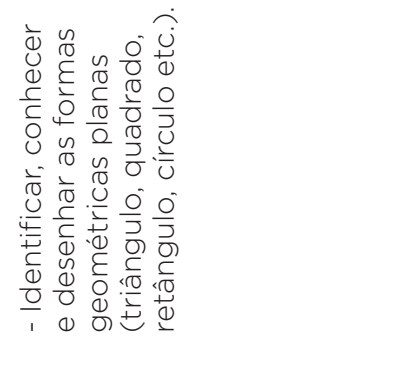 & 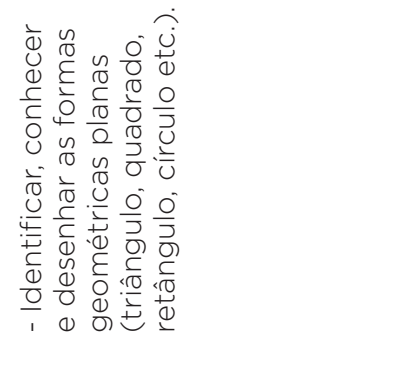 \\
\hline
\end{tabular}




\begin{tabular}{|c|c|}
\hline 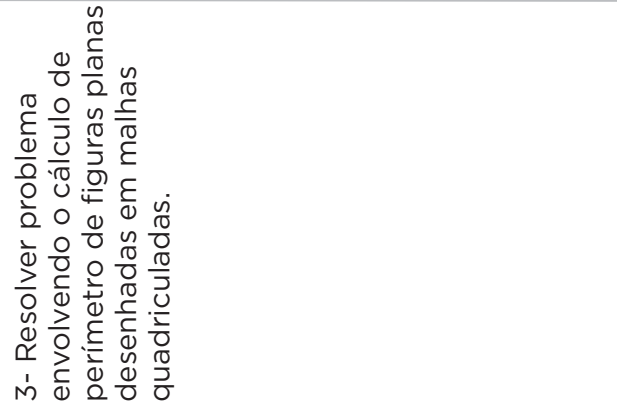 & 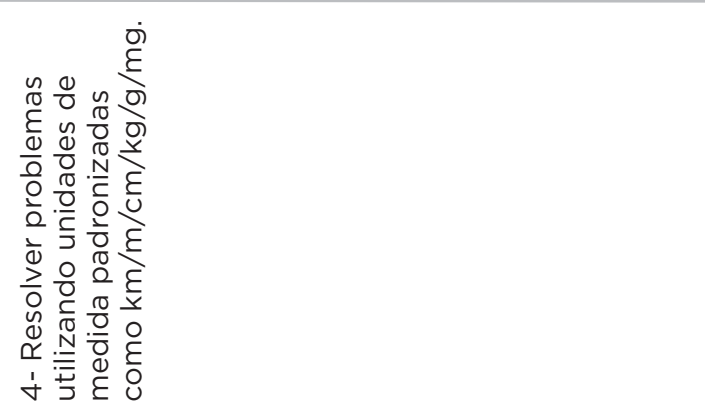 \\
\hline 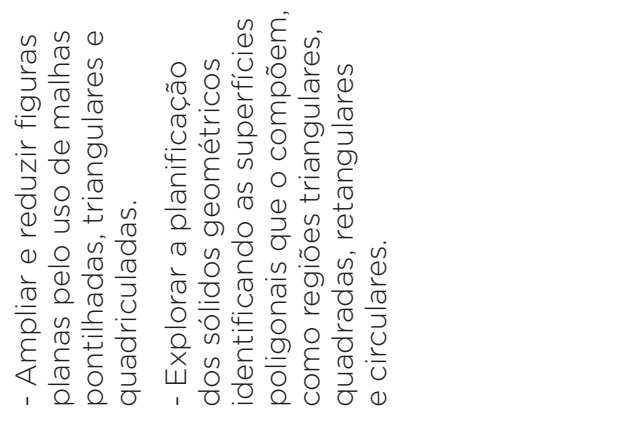 & 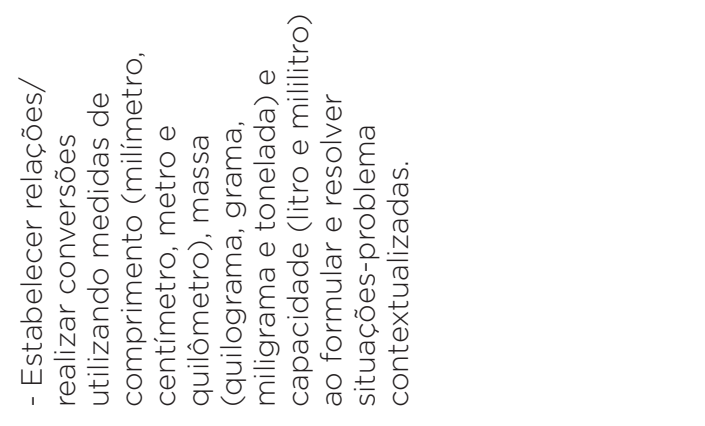 \\
\hline 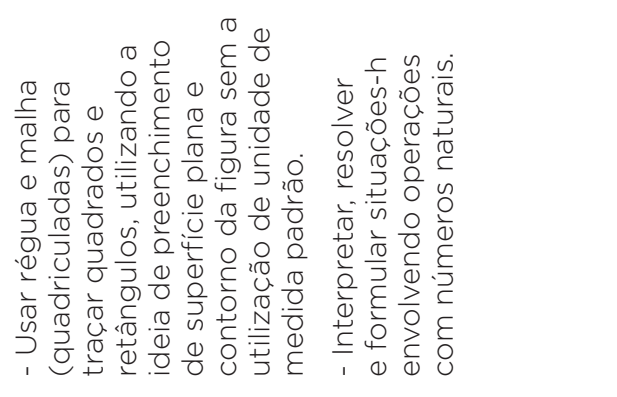 & 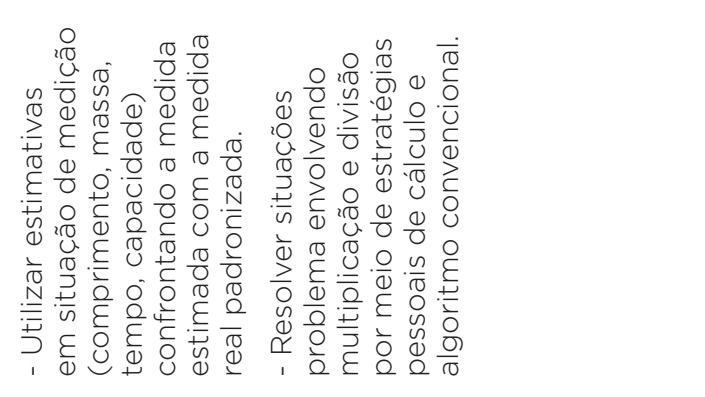 \\
\hline 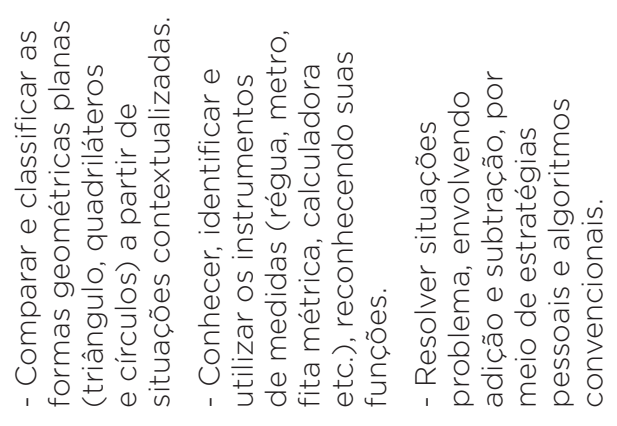 & 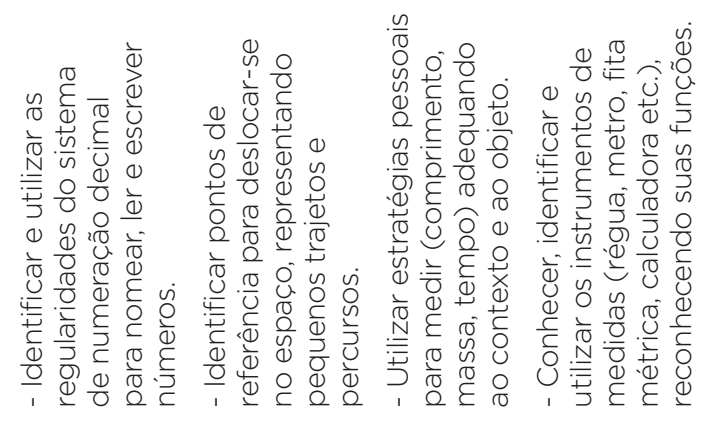 \\
\hline 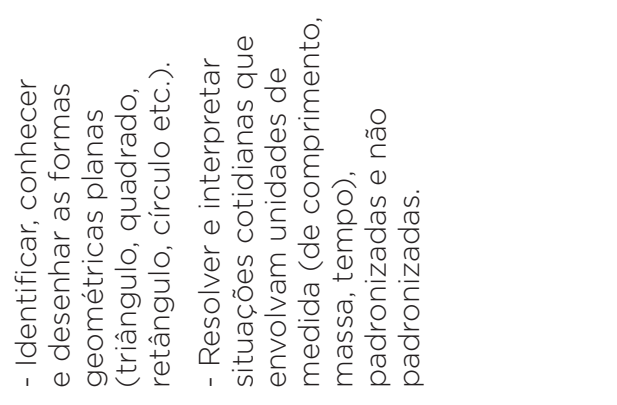 & 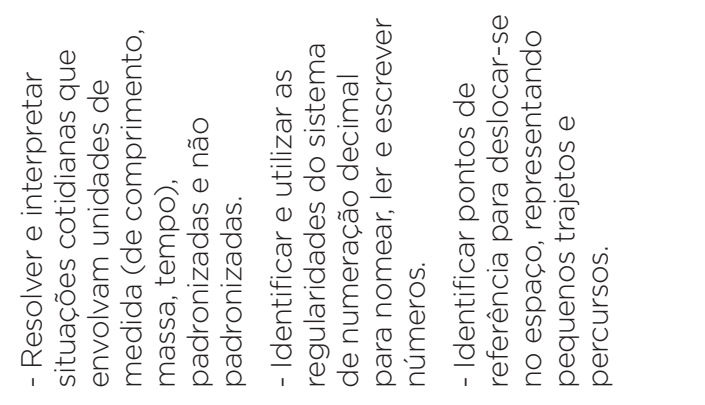 \\
\hline
\end{tabular}




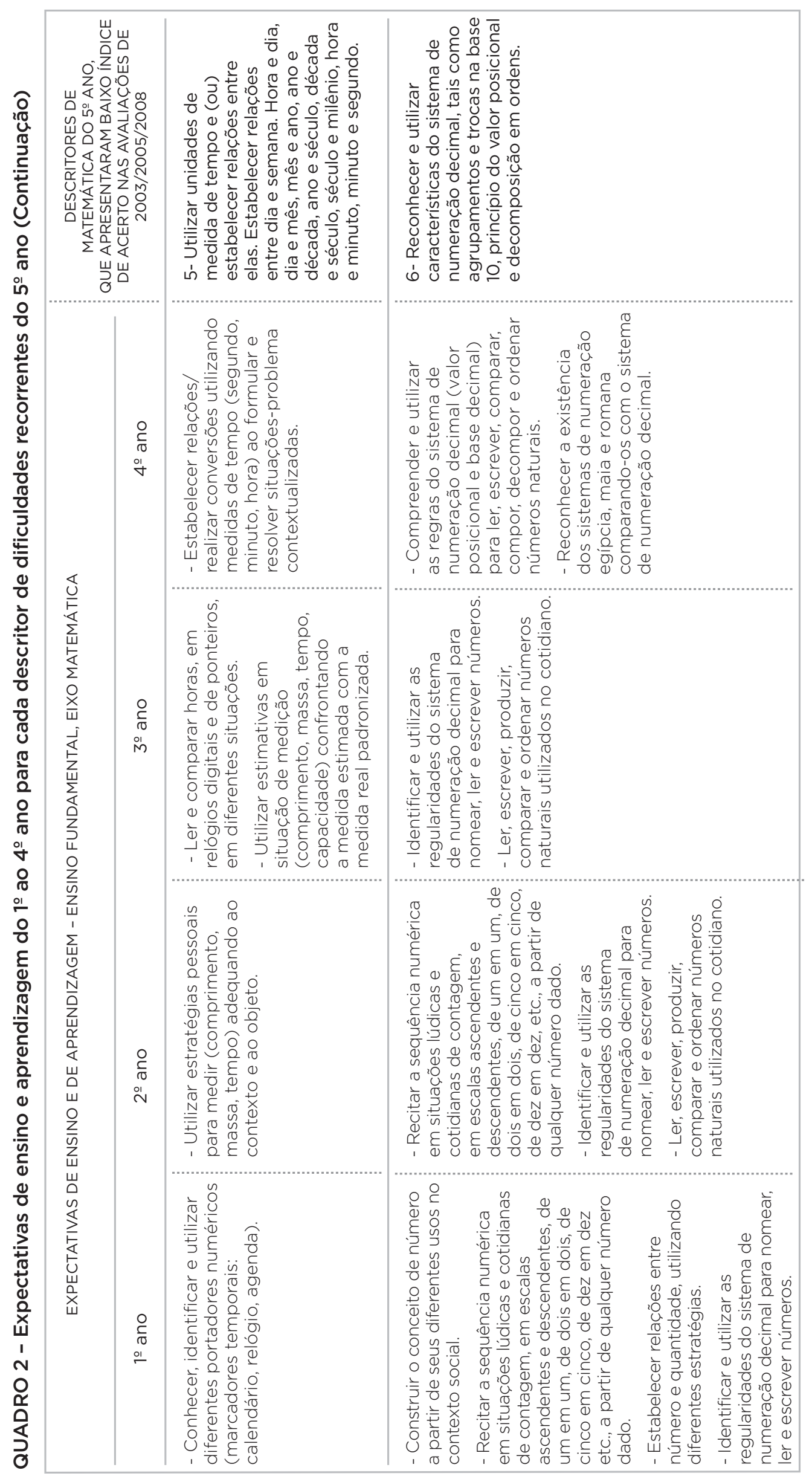




\begin{tabular}{|c|c|}
\hline 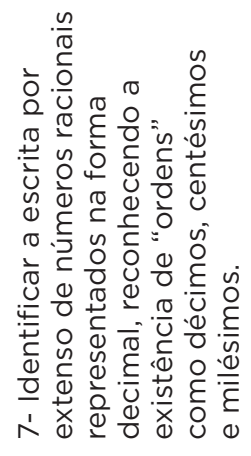 & 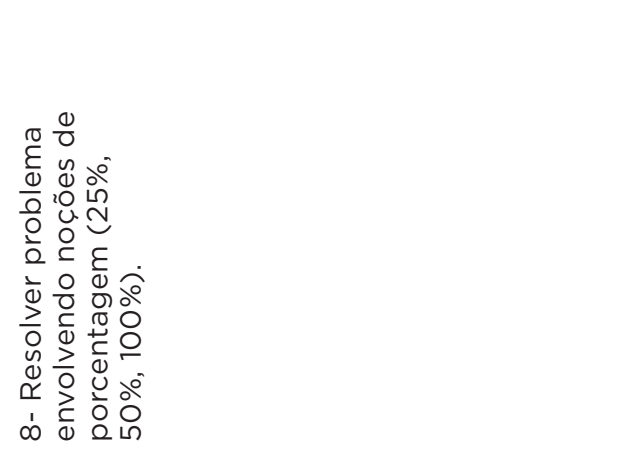 \\
\hline 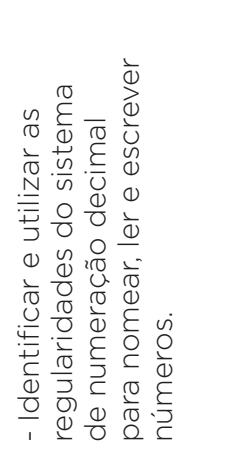 & 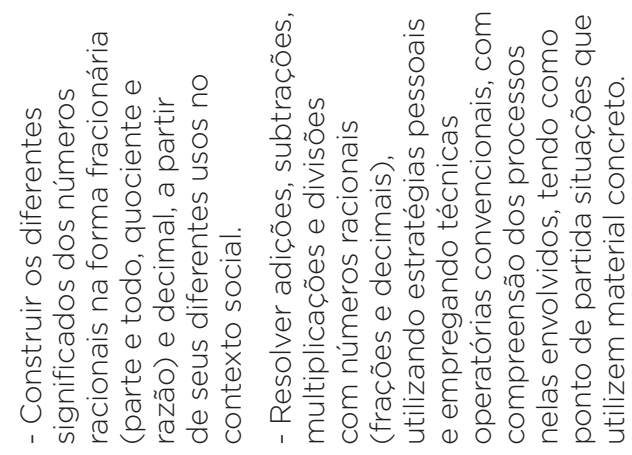 \\
\hline 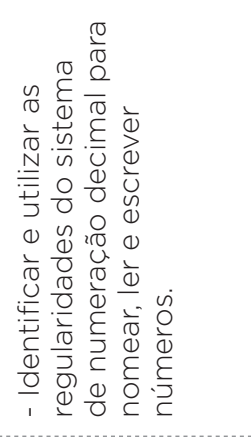 & 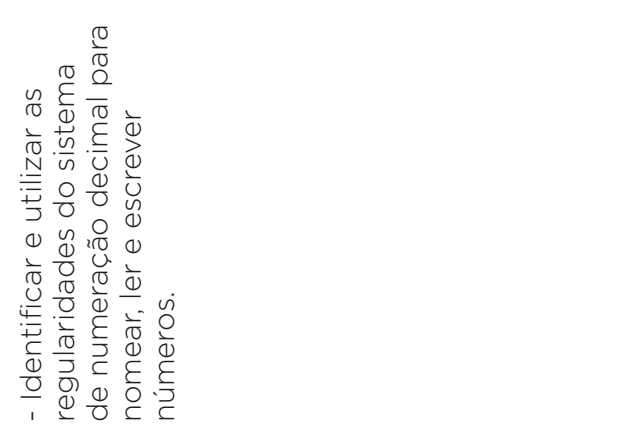 \\
\hline 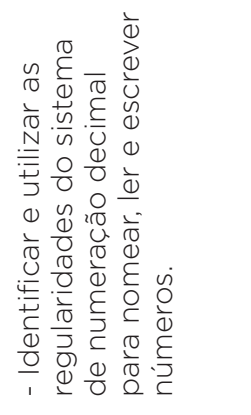 & 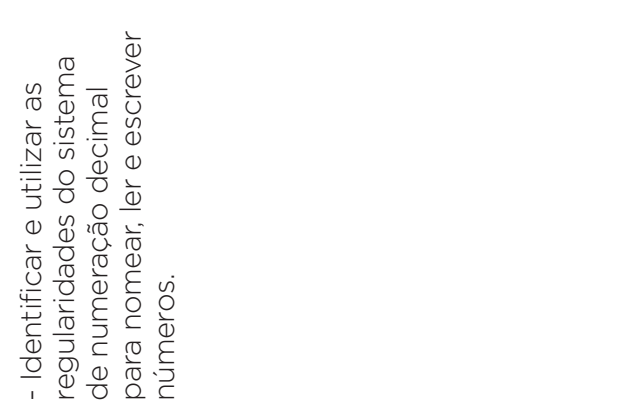 \\
\hline 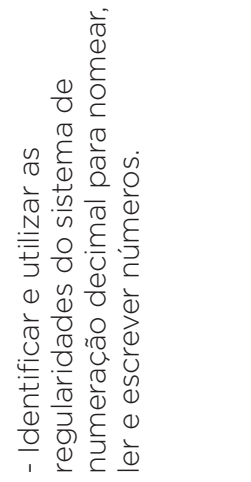 & 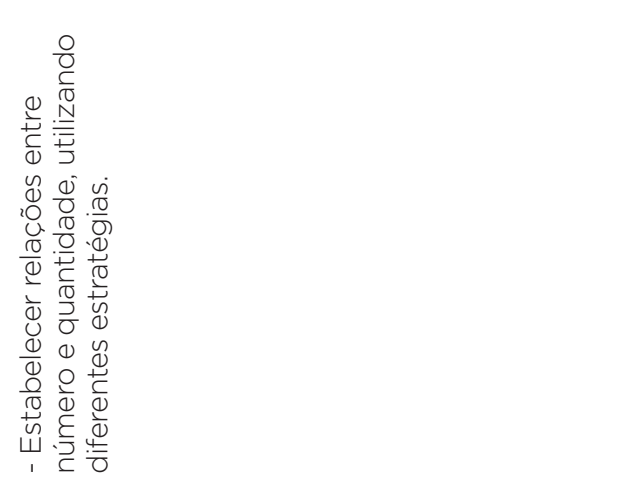 \\
\hline
\end{tabular}


A análise dessa etapa identificou conhecimentos e habilidades que deveriam ter sido desenvolvidos ao longo dos anos para que os alunos da $4^{\mathrm{a}}$ série $/ 5^{\circ}$ ano apresentassem resultados satisfatórios na avaliação a que foram submetidos. A intenção da análise foi compreender como estas expectativas - pré-requisitos - foram desenvolvidas e orientadas pela escola e pelo sistema de ensino e qual o conhecimento que os professores e a escola têm desses encadeamentos.

\section{3ํ ETAPA DA PESQUISA - ANÁLISE DA COMPREENSÃO DOS PROFESSORES EM RELAÇÃO ÀS DIFICULDADES IDENTIFICADAS}

O diagnóstico das dificuldades recorrentes poderia permitir identificar, além das próprias dificuldades, em que momento do processo escolar elas se instalaram, como os docentes estão as analisando e como poderiam superá-las. Por isso, nessa terceira etapa os professores de $5^{\circ}$ ano foram consultados, por meio de entrevistas, sobre tais dificuldades e, em seguida, procedeu-se à análise da compreensão que esses docentes tiveram em relação às dificuldades identificadas. As representações sociais apontadas pelos professores sobre estas dificuldades ofereceram condições para se observar como eles equacionam, em sua prática, os seus problemas e aqueles enfrentados pelos estudantes.

A análise das entrevistas com os 24 professores dos alunos que apresentaram as dificuldades recorrentes no $5^{\circ}$ ano envolveu dois momentos. No primeiro, esperava-se que o docente analisasse a origem das dificuldades dos estudantes, explicitando em que momento do percurso escolar ela se instalou e, em seguida, o que ele poderia fazer frente a essas dificuldades.

As questões que embasaram as análises desse primeiro momento, feitas ao professor, foram:

- Quais as principais dificuldades de seus alunos em Matemática?

- Como foram observadas essas dificuldades em anos anteriores (em outros alunos de $5^{\circ}$ ano)?

- Essas dificuldades persistem o ano todo?

- Vou apresentar as principais dificuldades que identificamos com os dados das avaliações externas, como você analisa cada uma dessas dificuldades? 
Já as análises referentes à atuação docente frente às dificuldades recorrentes foram realizadas com base nos seguintes questionamentos :

- O que deve ser feito para solucionar estas dificuldades?

- O que falta e o que poderia auxiliar na solução dessas dificuldades?

- Você tem alguma dificuldade em trabalhar esses tópicos em sala de aula? Quais?

- Esses conteúdos que apresentam dificuldades para os alunos estão previstos no seu plano de ensino nesse ano?

\section{ANÁLISE DAS PRINCIPAIS DIFICULDADES DOS ALUNOS, IDENTIFICADAS PELOS PROFESSORES}

A análise dos professores sobre as dificuldades recorrentes evidenciou que, para além de identificar o que os alunos não sabem, os diagnósticos que procurassem ouvir os processos e as dificuldades cotidianas dos professores favoreceriam o aprofundamento das análises e ofereceriam caminhos para solução desses problemas.

Em relação às principais dificuldades dos alunos em Matemática, inicialmente os docentes identificaram algumas dificuldades relacionadas aos números decimais - predominantemente frações e números decimais -, conceitos estes interligados com um conteúdo mais amplo referente a números racionais. Para os professores, o ensino da porcentagem torna-se mais fácil porque permite fazer uma relação com fração.

A maior dificuldade é fração, número decimal. A ideia de porcentagem, quando chegou, foi mais fácil para eles do que esses conceitos relacionados à fração. A fração, eu acho que é a pior dificuldade... fração e número decimal. (Prof. 11)

Assim como no caso das frações e porcentagens, os professores, ao analisarem as dificuldades dos alunos, ofereceram pistas de como as sequências didáticas e as estratégias deveriam ser seguidas. Observa-se que há um conhecimento construído na prática, que precisa ser identificado e explorado, para então ser contestado, discutido ou revisto. Efetivamente, sem considerá-lo não há como superar as dificuldades dos alunos. 
Outro exemplo, apontado pelos docentes, diz respeito às estratégias metodológicas, situações-problema e método de uso de material concreto que vêm sendo empregados como uma forma de desenvolver os conteúdos matemáticos do currículo. Comentam os professores:

A maior dificuldade é interpretação de uma situação-problema. Eles não conseguem identificar exatamente o que tem que ser feito, o que eles vão fazer para resolver aquela situação. Pode ser que seja uma questão de vocabulário, pois acho que as dificuldades de aprendizagem, de qualquer maneira, surgem porque essa criança tem um universo cultural muito pobre. (Prof. 20)

A dificuldade maior é a interpretação da situaçã-problema envolvendo operações que eles ainda têm dificuldade. (Prof. 15)

Ainda em relação às situações-problema, os professores indicam que:

[...] apesar de trabalhar no concreto, fazendo receitas, uma série de coisas, tem crianças que conseguem até entender essa parte, mas na hora que você vai dar operações com frações, principalmente com denominadores diferentes, aí dá um nó. (Prof. 10)

A partir da identificação e mapeamento das dificuldades, faz-se necessário buscar soluções para auxiliar os professores na resolução desses problemas, já que se trata de uma dificuldade do aluno, que o docente parece não conseguir superar. Se a sugestão de oferecer material concreto não está trazendo os resultados esperados, faz-se imediato pensar em outra metodologia para ensinar esses estudantes.

O diagnóstico dos professores indica, ainda, a possibilidade de identificar problemas que, na verdade, estão relacionados às condições das escolas e não poderiam ser atribuídas ao docente e muito menos ao aluno. Assim indica um dos professores:

Eu perguntei ao aluno que conta ele estava fazendo... "O que é isso?" Ele não sabia montar uma conta de adição. Ele veio do Estado (escola do Estado) e disse pra mim que desde o primeiro ano, segundo ano, terceiro ano, quarto ano, ele nunca tinha tido uma aula de Matemática. (Prof. 12)

Resumidamente, dos 24 professores entrevistados, 11 afirmaram que as dificuldades foram observadas em anos 
anteriores, isto é, eles reconhecem que as dificuldades são recorrentes. Destes, 8 afirmaram que a origem do problema está, principalmente, na dificuldade de os alunos compreenderem uma situação-problema como, por exemplo, a abstração que precisam fazer para, depois de uma situação concreta, entender como se opera com frações.

Procurando aprofundar as análises, foi solicitado aos professores que verificassem cada uma das habilidades apresentadas no quadro 1 e indicassem as dificuldades dos alunos. Os resultados são apresentados na tabela 1, a seguir:

TABELA 1 - Dificuldades dos alunos reconhecidas pelos professores

\begin{tabular}{|c|c|c|c|c|c|c|c|c|}
\hline $\begin{array}{l}\text { DIFICULDADE } \\
\text { APONTADA } \\
\text { PELOS } \\
\text { PROFESSORES }\end{array}$ & $\begin{array}{c}\text { FIGURAS } \\
\text { TRIDIMENSIONAIS }\end{array}$ & $\begin{array}{c}\text { FIGURAS } \\
\text { BIDIMENSIONAIS }\end{array}$ & $\begin{array}{l}\text { UNIDADES } \\
\text { DE MEDIDA } \\
\text { DE MASSA/ } \\
\text { COMPRIMENTO }\end{array}$ & PERÍMETRO & $\begin{array}{l}\text { UNIDADES } \\
\text { DE MEDIDA } \\
\text { DE TEMPO }\end{array}$ & $\begin{array}{l}\text { SISTEMA } \\
\text { DECIMAL }\end{array}$ & $\begin{array}{l}\text { NÚMEROS } \\
\text { RACIONAIS }\end{array}$ & PORCENTAGEM \\
\hline Descritor & Descritor 1 & Descritor 2 & Descritor 3 & Descritor 4 & Descritor 5 & Descritor 6 & Descritor 7 & Descritor 8 \\
\hline $\begin{array}{l}\text { Número de } \\
\text { professores } \\
\text { que } \\
\text { reconhece } \\
\text { o descritor } \\
\text { como } \\
\text { dificuldade }\end{array}$ & 11 & 8 & 17 & 7 & 11 & 8 & 12 & 7 \\
\hline
\end{tabular}

Os professores entrevistados, além de apontarem as problemáticas específicas dos conteúdos, identificaram as dificuldades de se trabalhar com conteúdos abstratos, com materiais concretos e de transferir os estudos de materiais concretos para conceitos abstratos, o que pode ser verificado na tabela 2 :

TABELA 2 - Dificuldades de trabalhar com conteúdo abstrato e material concreto

\begin{tabular}{|c|c|c|c|c|c|c|c|c|}
\hline & $\begin{array}{c}\text { DESCRITOR } \\
1\end{array}$ & $\begin{array}{c}\text { DESCRITOR } \\
2\end{array}$ & $\begin{array}{c}\text { DESCRITOR } \\
3\end{array}$ & $\begin{array}{c}\text { DESCRITOR } \\
4\end{array}$ & $\begin{array}{c}\text { DESCRITOR } \\
5\end{array}$ & $\begin{array}{c}\text { DESCRITOR } \\
6\end{array}$ & $\begin{array}{c}\text { DESCRITOR } \\
7\end{array}$ & $\begin{array}{c}\text { DESCRITOR } \\
8\end{array}$ \\
\hline $\begin{array}{l}\text { Conteúdo } \\
\text { abstrato } \\
\text { (quantidade } \\
\text { de sujeitos) }\end{array}$ & 07 & 06 & 05 & 01 & 05 & 04 & $\mathrm{O} 2$ & $\mathrm{O} 2$ \\
\hline $\begin{array}{l}\text { Material } \\
\text { Concreto } \\
\text { (quantidade } \\
\text { de sujeitos) }\end{array}$ & 13 & 08 & 03 & 04 & 04 & 08 & 04 & 01 \\
\hline
\end{tabular}


3 Alceste - Analyse Lexicale par Contexte d'un Ensemble de Segments de Texte Version 4.7 pour Windows (REINERT, 1986) - trata-se de uma ferramenta adequada tanto para a análise de representações sociais, quanto para o processamento de textos que compõem um corpus razoavelmente grande.
As observações e questões propostas pelos professores apontam problemas reais, importantes, que devem ser analisados por especialistas em processos de aprendizagem, de modo a fazer jus a um processo avaliativo que se aprofunda e alcança objetivos concretos, processos reais e se propõe a mudanças efetivas.

\section{ANÁLISE DA COMPREENSÃO DOS PROFESSORES \\ SOBRE SUA FUNÇÃO FRENTE ÀS DIFICULDADES IDENTIFICADAS DOS ALUNOS}

Com relação às analises desse entendimento, por parte dos professores, o processamento realizado pelo Alceste $^{3}$ identificou três categorias de respostas, que pretendem descrever as visões que esses docentes apresentam sobre as dificuldades identificadas nos alunos.

a. professor (individual): refere-se à categoria de respostas dos docentes que procuram sanar as dificuldades dos estudantes, buscando ações individuais. O professor utiliza-se de métodos como a recuperação individual do aluno, a atividade física e o feedback como recursos para ajudar o estudante na superação de tais dificuldades.

Você vai resolver a dificuldade daquela criança individualmente no dia a dia da sala de aula, na dinâmica da rotina. (Prof. 17)

[...] é o que eu disse para você, a gente faz muito, devolutiva e análise do erro, toda atividade que você desenvolve com o aluno e a gente num determinando momento volta e corrige, e para mim é um feedback [...]. (Prof. 3)

Também são reunidas, nessa categoria, as justificativas individuais do docente, que responderiam pelas dificuldades dos alunos. Assim, relatam os professores que a dificuldade está centrada na quantidade de conteúdo disciplinar proposta para $5^{\circ}$ ano, em tão curto espaço de tempo.

o nosso tempo é muito curto e o conteúdo é muito grande. Vocês já deram uma olhada nos nossos conteúdos, por curiosidade? E tem quedar conta dele. Tem também que se ter criatividade. Mas, se eu tivesse uma hora a mais no meu dia seria ótimo. (Prof. 1) 
A falta de tempo do docente para preparação das aulas é outro aspecto relatado pelo professor quando se observam as dificuldades individuais:

Falta tempo porque tem uma grande quantidade coisas para fazer e você tem que dar conta. Você pode dizer, mas você não fica oito horas na escola. Mas tem Português, História, Matemática, Geografia, Ciências, Educação Física e Artes, tudo no nosso livro. Tem muita pesquisa e bastante coisa para fazer [...]. (Prof. 2)

Nessa categoria, as informações que definem as representações sociais têm como referências as dificuldades pessoais do docente e as atividades que individualmente elabora para dar conta dessas dificuldades. Verifica-se um esforço pessoal para atender às dificuldades do aluno, mas, ao mesmo tempo, uma angústia que se expressa pela falta de tempo para dar conta de todas as atividades propostas pelo método.

b. institucional: relata soluções criadas para dar conta das dificuldades dos alunos e dos problemas que deveriam ser tratados institucionalmente como formação do docente, professores auxiliares de classe, etc.

São analisadas, também nesta categoria, as estratégias institucionais utilizadas para recuperação contínua, como, por exemplo, os cadernos amarelos citados por alguns professores. Este processo, no entanto, não é considerado pelos docentes como efetivo na superação das dificuldades. As propostas institucionais de recuperação do aluno parecem ser discriminatórias no relato dos professores:

Este caderno amarelo funciona, entre aspas, como uma recuperação. Às vezes, ele pode ser feito na sala, eu forço os pais, não vou te negar, eu mando pra casa, às vezes vem errado. Impressionante! (Prof. 8)

[...] existem as provas normais, quando é apresentada a folha branca, a comum, o pai vê que aquela prova é o nível da sala, ele observa que seu filho está na amarela, significa que ele não atingiu o esperado. (Prof. 10)

Observa-se, ainda, que esses docentes atribuem aos pais grande parte da responsabilidade do desempenho dos alunos, mas compreendem que tais incumbências deveriam ser cobradas pela escola: 
O que poderia ajudar muito nessa solução é a escola criar mecanismos que forçassem os pais a participarem da vida das crianças. Penso que, no nosso caso, a instituição é muito solta, muito complacente com muitas coisas, nós temos problemas indisciplinares com alunos e pouquíssimas atitude; somente em casos extremos os alunos são transferidos de unidade. Se a família trabalhasse junto diminuiria noventa e nove vírgula nove por cento, eu acho, do que falta hoje. E eu falo pra você uma coisa com sinceridade: a minha sala este ano é uma sala que eu tenho um pouco de dificuldade, porque são filhos de pais separados. (Prof. 9)

Ainda no nível institucional, as propostas institucionais de não reprovação do aluno continuam com dificuldades de aceitação entre os professores:

[...] tipo de coisa que realmente tem que estudar. Mas não. 0 aluno vem, ele não entrega trabalho, não entrega nota e nós não podemos reprovar, nós não podemos dar vermelho. (Prof. 11)

[...] porque eles não te entregam, eles não tem responsabilidade de trazer pesquisa, trabalho, seminário, eles não estudam para prova. Avacalhou demais, sabe [...]. (Prof. 19)

[...] num primeiro bimestre, você realmente dá vermelha, pelo o que ele tirou. Seria come se fosse um chacoalhão, para pai e mãe enxergar as dificuldades do seu filho. (Prof. 23)

É também no nível institucional que estão agrupadas as responsabilidades pela formação continuada. Para os professores, a responsabilidade por sua formação deve ser atribuída à instituição. Eles indicam:

[...] acho que falta capacitação. O professor, às vezes, ele ignora alguma coisa, não e porque ele quer é porque ele realmente não conhece, então falta essa capacitação. Eu acho que falta investimento em profissionais dessa área, principalmente a Matemática, porque tem tanta gente boa, tem tanta gente publicando coisas interessantes por ai, tanta gente ministrando cursos, enfim, faltam boas capacitações. (Prof. 20)

[...] material aqui, embora tenha melhorado bastante, mas eu acho que ainda falta um pouco mais de formação. Eu sinto falta de mais um pouco de formação. Estou há quarenta anos no magistério e eu 
ainda aprendi como fazer certas coisas ainda diferentes e que são melhores do que eu fazia antes. (Prof. 21)

Ainda no tópico referente à formação continuada, os professores foram questionados sobre quais dificuldades encontravam ao trabalhar os tópicos apresentados no quadro de descritores da pesquisa (Quadro 1), em sala de aula. Das respostas, depreende-se que, para o docente, os conteúdos mais dificeis de serem trabalhado são as medidas padronizadas e de tempo, número decimal e fração. Percebe-se, no entanto, que a maior dificuldade apresentada pelos docentes não é o conteúdo, mas a transposição didática, o que eles também justificam como sendo uma dificuldade de interpretação de texto por parte do aluno.

[...] quando você quer que o aluno entenda. Por exemplo, quando você resolve alguma coisa muito prática, eu vou calcular uma porcentagem, então você tem dificuldade em explicar aquilo quando você utiliza somente de estratégias muito práticas, às vezes eu tenho dificuldade nisso. O que eu tenho que fazer antes em casa eu olho e falo isso aqui e fácil porque eu sei para mim porque estou prática, mas como eu vou explicar mesmo. (Prof. 21)

Não tenho dificuldades de trabalhar esses descritores. A questão mesmo é quando envolve a leitura, porque a parte da figura eles compreendem visualizando ali. (Prof. 22)

[...] sim, na questão da relação do número decimal com a fração. A gente até retomou o conteúdo, usou alguns jogos, mas eu senti uma dificuldade sim. (Prof. 23)

Quanto às soluções em nível institucional, os professores relatam, em primeiro lugar, a importância da participação dos pais. Os docentes apresentam estratégias importantes e relevantes que deveriam ser consideradas em processos de planejamento institucional. Referem-se à presença de um auxiliar na sala de aula ou de um monitor:

O que falta, acredito, para aqueles alunos que têm maior dificuldade, terem uma pessoa em sala de aula, um estagiário mesmo, que cada sala pudesse dar um apoio, e enquanto o professor está com a sala.

(Prof. 24) 
[...] ou que fosse assim uma profissional na escola, nos auxiliaria bastante. Nosso trabalho todo dia, esse caminhar assim todo dia, você vendo o aluno com essa dificuldade e você com a sala toda [...]. (Prof 19)

Nessa categoria, as informações que integram as representações sociais dos docentes sobre as dificuldades recorrentes dos alunos evidenciam que eles atribuem a solução desses problemas a ações institucionais.

c. grupo de professores: relata categorias de respostas que procuram identificar como os docentes procuram se ajudar através da troca de experiências. Informam, também, sobre a importância de processos de formação continuada para todos os professores.

[...] nos vivemos escola. São nesses momentos que nós conseguimos desabafar e, às vezes, ajudar. ..."Por que você não faz assim? Vamos tentar fazer assado?" É nessas horas, também, que nos procuramos também ver, buscar a estratégia que vamos usar. (Prof. 12)

\section{CONCLUSÕES}

O professor constrói representações que permitem amenizar o conflito da não aprendizagem e dos resultados das avaliações em larga escala, tais como: falta de apoio da família; pouco tempo; formação universitária insuficiente; ausência de material didático; pressão administrativa para a não reprovação. Essas representações se constituem como um discurso anônimo, que respondem a toda e qualquer dificuldade e não evidenciam implicações pessoais subjetivas com o processo de aprendizagem. Mas, por outro lado, oferecem sugestões e análises feitas que, se ouvidas, permitiriam superar muitas das dificuldades apresentadas.

O estudo evidenciou que os professores têm condições de aprofundar diagnósticos qualitativos que permitiriam compreender como atuar frente às dificuldades recorrentes dos alunos. Esses docentes, por não saberem identificar as origens destas dificuldades, acabam criando hipóteses diversas, desde a culpabilização dos pais, até a atuação das próprias crianças. No entanto, quando indagados sobre como enfrentar 
tais dificuldades, oferecem sugestões institucionais que deveriam ser consideradas pelos sistemas de ensino.

Nesse ponto, o que este estudo permitiu concluir é que uma avaliação de larga escala não somente se aprofunda e cria condições para se tornar efetiva quando ouve a experiência do professor, quanto analisa suas dificuldades e compreende suas contradições e seus não ditos.

\section{REFERÊNCIAS}

BROOKE, N; SOARES, J. F. Pesquisa em eficácia escolar - origem e trajetórias. Belo Horizonte: UFMG, 2008.

BRASIL. Parecer CNE/CEB, n. 15, de $1^{\circ}$ de junho de 1998. Diretrizes Curriculares Nacionais para o Ensino Médio. Brasília: Conselho Nacional de Educação, 1997. Disponível em: <http://www.mec.gov.br>. Acesso em: mar. 2001.

CAMARGO, B. V. ALCESTE: Um programa informático de análise quantitativa de dados textuais. In: MOREIRA, A. S. P et al. (Org.). Perspectivas teórico-metodológicas em representações sociais. João Pessoa: UFPB, 2005. p. 511-539.

FREITAS, D. N. T. de. Avaliação da educação básica e ação normativa federal. Cadernos de Pesquisa, São Paulo, v. 34, n. 123, p. 663-689, São Paulo: 2004.

FUNDAÇÃO CARLOS CHAGAS. Relatório final da avaliação do desempenho dos alunos da $4^{\mathrm{a}}$ série de 2003. São Paulo, 2003.

MOSCOVICI, S. A Psicanálise, sua imagem e seu público. Tradução de Sonia Fuhrmann. Petrópolis: Vozes, 2012. . La Psychanalyse, son image et son public. Paris: PUF, 1961. . A Representação social da psicanálise. Rio de Janeiro: Zahar, 1978. . Representações sociais: investigações em psicologia social. Petrópolis: Vozes, 2003.

REINERT, M. Manuel d'utilisation ALCESTE. Toulouse: IMAGE, 1986. Version 4.7 pour Windows.

TAVARES, A. V. Avaliação de larga escala: resultados e tomada de decisão. Dissertação (Mestrado em Psicologia da Educação) - Pontifícia Universidade Católica de São Paulo, São Paulo, 2012.

UNIVERSIDADE DE BRASÍLIA. Resultados da avaliação educacional dos alunos da $4^{\underline{a}}$ série de 2005. Brasília: CESPE, 2005. . Resultados da avaliação educacional dos alunos da 4ª série de 2008. Brasília: CESPE, 2008. 


\section{CLARILZA PRADO DE SOUSA}

Professora titular da Pontifícia Universidade Católica de São Paulo - PUC/SP. Coordenadora do Centro Internacional de Estudos em Representações Sociais e Subjetividade-Educação - Ciers-Ed, da Fundação Carlos Chagas - FCC clarilza.prado@uol.com.br

\section{TARCISO JOAQUIM DE OLIVEIRA}

Mestrando do Programa de Pós-Graduação de Educação: Psicologia da Educação da Pontifícia Universidade Católica de São Paulo - PUC/SP. Professor da Universidade Paulista - Unip tarcis@hotmail.com

\section{MARIA CONCEIÇÃO ROCHA}

Mestranda do Programa de Pós-Graduação em Educação: Psicologia da Educação da Pontifícia Universidade Católica de São Paulo - PUC/SP mariepuc@hotmail.com

\section{IVO RIBEIRO DE SÁ}

Doutorando do Programa de Pós-graduação de Educação: da Pontifícia Universidade Católica de São Paulo - PUC/SP. Professor da Universidade Municipal de São Caetano do Sul ivo.rsa@terra.com.br

\section{SOLANGE MARIA DOS SANTOS}

Mestra no Programa de Pós-Graduação de Educação

Matemática da Pontifícia Universidade Católica de São Paulo - PUC/SP. Professora do Estado de São Paulo, PEB II matemática. Analista técnica educacional, na Gerência de Avaliação da rede do Serviço Social da Indústria - Sesi langesolii@gmail.com

\section{SIMONE DE OLIVEIRA ANDRADE SILVA}

Bolsista do CNPq no Mestrado do Programa de Pós-Graduação em Educação: Psicologia da Educação da Pontifícia Universidade Católica de São Paulo - PUC/SP sisiol01@hotmail.com 


\section{LEILA YURI SUGAHARA}

Doutoranda pelo Programa de Estudos Pós-Graduados em Educação: Psicologia da Educação da Pontifícia Universidade Católica de São Paulo - PUC/SP

leila@rededuc.com

\section{KARINA ALVES BIASOLI STANICH}

Mestranda no Programa de Pós-Graduação de Educação:

Psicologia da Educação da Pontifícia Universidade

Católica - PUC/SP

karinabiasoli@yahoo.com.br

\section{ANTONIO VANDERLEI TAVARES}

Mestre em Educação pelo Programa de Estudos Pós-

Graduados em Educação: Psicologia da Educação da Pontifícia

Universidade Católica de São Paulo - PUC/SP

antonitavares@uol.com.br 